\title{
Chest and facial surgery for the transgender patient
}

\author{
Melody Scheefer Van Boerum ${ }^{1}$, Ara A. Salibian², Rachel Bluebond-Langner ${ }^{2}$, Cori Agarwal ${ }^{1}$ \\ ${ }^{1}$ Division of Plastic Surgery, University of Utah, Salt Lake City, UT, USA; ${ }^{2}$ Hansjörg Wyss Department of Plastic Surgery, NYU Langone Health, \\ New York, NY, USA \\ Contributions: (I) Conception and design: C Agarwal, R Bluebond-Langner; (II) Administrative support: None; (III) Provision of study materials or \\ patients: None; (IV) Collection and assembly of data: All authors; (V) Data analysis and interpretation: None; (VI) Manuscript writing: All authors; \\ (VII) Final approval of manuscript: All authors. \\ Correspondence to: Cori Agarwal, MD. Division of Plastic Surgery, Department of Surgery, University of Utah, 30N 1900E 3b400, Salt Lake City, UT \\ 84132, USA. Email: cori.agarwal@hsc.utah.edu.
}

\begin{abstract}
In conjunction with social transition, hormones, and counseling, gender-affirming surgery (GAS) is a key component in the treatment gender dysphoria. Gender affirming surgeries can be divided into genital surgery (phalloplasty, metoidioplasty, oophorectomy, vaginoplasty, and orchiectomy) and non-genital surgeries. The non-genital surgeries for transmasculine individuals include chest masculinization and body contouring. For transfeminine individuals, they include breast augmentation, and facial feminization. Chest masculinization eliminates the need for binding and improves overall confidence and quality of life. Choice of technique depends on body habitus and patient preference. For transfeminine individuals, some breast growth can be achieved with the use of estrogen over the course of 1-2 years, but many still require breast augmentation for breasts that are proportionate to their frame. Facial surgery for transfeminine patients is highly effective in changing classic masculine anatomic features to feminine norms. The most common of these procedures include forehead contouring, rhinoplasty, lip lift, mandible angle reduction, genioplasty and chondrolaryngoplasty. These non-genital surgeries are critical to treating gender dysphoria in transgender and gender non-binary individuals. Further research with standardized and validated assessments of patient reported outcomes is needed to fully understand long term effects on quality of life and gender dysphoria.
\end{abstract}

Keywords: Transgender; top surgery; facial feminization surgery (FFS); chest masculinization

Submitted Jun 03, 2019. Accepted for publication Jun 20, 2019.

doi: $10.21037 /$ tau.2019.06.18

View this article at: http://dx.doi.org/10.21037/tau.2019.06.18

\section{Introduction}

Gender dysphoria refers to the significant distress that results from an incongruence between the sex assigned at birth and the individual's gender identity (1). Social transition, hormones and gender-affirming surgery (GAS) can be effective in the medical treatment of gender dysphoria. Transgender and gender non-binary individuals may choose to undergo one or more surgical procedures depending on their individual goals. The World Professional Association for Transgender Health (WPATH) sets forth Standards of Care guidelines for surgical and nonsurgical treatment of the transgender and gender nonbinary individual (2). Gender affirming surgeries can be divided into genital surgery (phalloplasty, metoidioplasty, oophorectomy, vaginoplasty, and orchiectomy) and nongenital surgeries. The aim of this article is to provide an overview of this latter group of gender affirming surgeries, specifically chest surgery and facial surgery.

Chest masculinization is one of the most common surgeries for transmasculine individuals. In the 2015 U.S. Transgender Survey, which surveyed 27,715 respondents, $97 \%$ of those who identified as transmen and $73 \%$ of non-binary individuals assigned female at birth (AFAB) reported either having already had top surgery or desiring it in the future (3). Breast augmentation for transfeminine individuals was desired in $44 \%$, with $8 \%$ having undergone breast augmentation and $36 \%$ desiring it in the future. 
Facial feminization, which can include a number of different surgeries of the facial skeleton including modification to the brow, hairline, eyelids and orbits, nose, face, and jawline, was reported to be either attained or desired in $45 \%$ of transwomen.

\section{Chest masculinization}

Chest masculinization, often referred to as "top surgery," is the most common surgical procedure for the transmasculine individual (3-5). Many of these patients bind their breasts daily with tight wraps and restrictive garments to conceal them. Binding is universally understood to be cumbersome, uncomfortable, and can lead to rashes, acne, and difficulty breathing. At least one study traced mildly elevated prolactin levels to mechanical compression (6). A growing body of literature definitively demonstrates improved quality of life, improved self-esteem and body image, and reduction in gender dysphoria in individuals who have undergone chest masculinization (7-11).

Readiness for chest masculinization is typically determined in a multidisciplinary fashion, including evaluation from a mental health professional. Current WPATH Standards of Care v.7 propose the following criteria: (I) persistent well documented gender dysphoria (ideally with 1 letter of support from a qualified mental health professional); (II) capacity to make a fully informed decision and to consent for treatment; (III) age of majority; and (IV) well controlled medical or mental health concerns. While testosterone therapy is often initiated prior to chest masculinization, it is not a requirement. For adolescents, the guidelines suggest that the patient live for an "ample" time as male and that they undergo testosterone treatment for one year. The described intent is, "to give adolescents sufficient opportunity to experience and socially adjust in a more masculine role, before undergoing irreversible surgery." The guidelines acknowledge, however, that there are specific clinical situations for adolescent patients in which a year of testosterone may not be indicated.

Prior to mastectomy, the Endocrine Society and American Cancer Society recommend breast cancer screening in the form of mammography, starting at the age of 45 , or as early as 40 if preferred by the patient. Post mastectomy recommendations include annual clinical breast exam of the chest wall, skin and incisions (12). Obese patients are encouraged to lose weight to lower BMI. Smoking cessation is highly recommended, as there are known risks of wound healing complications. All nicotine products should be stopped a minimum of 4 weeks prior to surgery, and not started until at least 4 weeks postoperatively (13). The risk of venous thromboembolism is not well studied in patients on testosterone supplementation, although with the theoretical risk of aromatization of testosterone to estradiol, discontinuing testosterone for a period of time before surgery is advocated by some surgeons. Due to the known elevation of hematocrit levels with testosterone treatment, evaluation for polycythemia is advisable prior to surgery. However, a recent systematic review did not demonstrate any association of increased VTE with or other complications after surgery with perioperative testosterone use (14).

A variety of surgical techniques for mastectomy in the transmasculine individual have been described, with the common goals of providing smooth masculine chest contours, minimize and camouflage scars along anatomic lines, and creating an aesthetic male nipple areolar complex (NAC) (4,5,15-20). Choice of technique is based on multiple factors including breast size, degree of skin laxity, degree of ptosis, skin quality, and the size and position of the NAC. In technique selection, one must balance the desire to limit the extent of the scar with obtaining an optimal chest contour. The preferences of the patient regarding scars, willingness to undergo revision surgeries, and maintenance of NAC sensitivity are factored into the technique selected.

Techniques can be classified into two basic categories: (I) long scar techniques, commonly called "double incision" technique with nipples transferred as free grafts or on an inferior pedicle; and (II) short scar techniques including periareolar, circumareolar, or other skin resection patterns around the areola with the nipples on a superior pedicle. The double incision techniques are the most common performed and can be used for patients with nearly any degree of skin laxity and breast ptosis (18). In order to achieve flat contours, the NACs are removed and replaced as skin grafts in the correct size, shape, and position to achieve male NAC aesthetics. This technique most consistently results in a flat chest without excess skin and effectively resizes and repositions the NACs. Sensation of the nipples is generally lost. The long scars are ideally positioned along the inferior insertion of the pectoralis muscle for optimal camouflage (Figure 1). It is also possible to keep the NACs connected on an inferior pedicle, which has the benefit of possible retained sensation and improved contours, but this comes at the cost of a noticeable bulge along the chest wall and is often not acceptable aesthetically. Among the short scar techniques, the periareolar approach is performed 

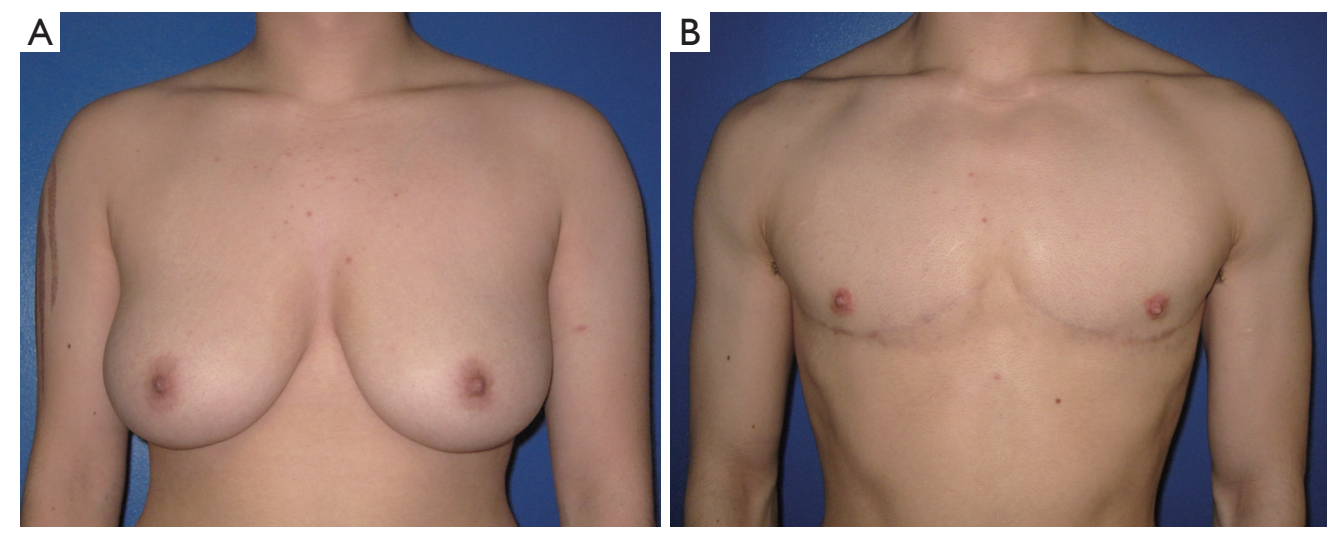

Figure 1 Chest masculinization using a double incision with free nipple graft technique. (A) Before; (B), after.
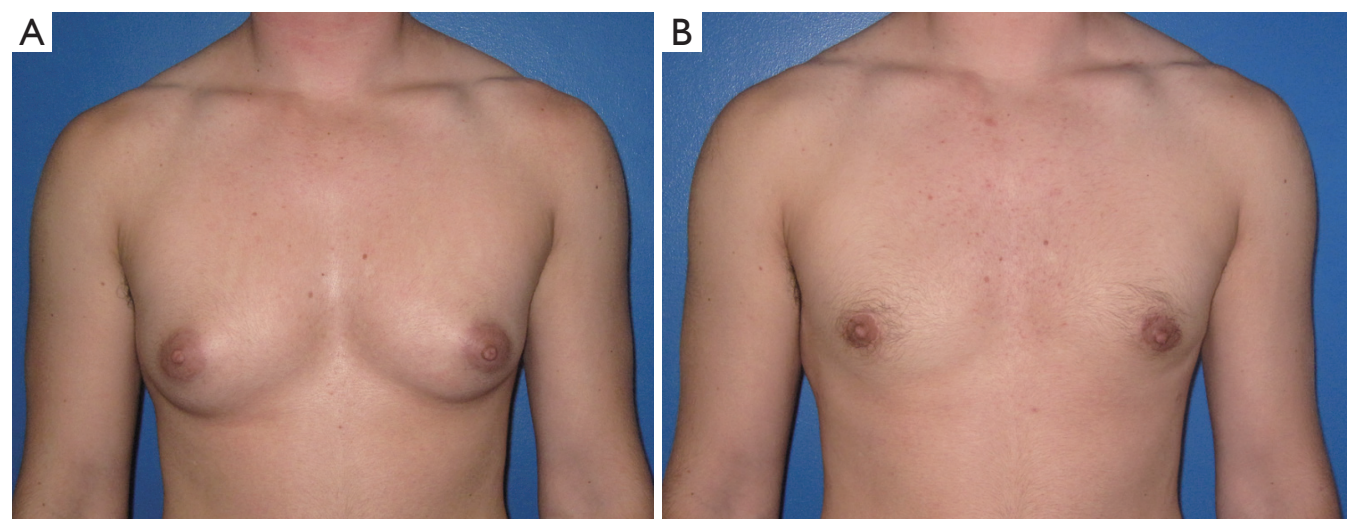

Figure 2 Chest masculinization using a limited scar, circumareolar technique. (A) Before; (B) after.

through a small incision along the inferior border of the areola and yields excellent results in small, non-ptotic breast with small areolas and good skin quality. In somewhat larger breasts with a small amount of ptosis, or larger nipple areola complexes, a concentric circular technique with occasionally other skin excision patterns, allows for small amounts of skin and areolar reduction at the time of mastectomy (Figure 2). These latter two techniques rely on shrinkage of the skin envelope after the surgery, which is unpredictable in most patients.

Postoperative recovery typically requires 4-6 weeks of no heavy lifting, and for those with free nipple grafts, will also include up to 3 weeks of wound care. Drains are commonly left in place for 1 week and a compression vest for a total of 3 weeks to prevent seroma formation. The most common complication is hematoma, ranging from $3-15 \%$, with a higher rate in the limited scar techniques, likely due to the reduced visibility during dissection $(16,17,20,21)$.
Other complications include seroma formation and infection, which are relatively low and typically managed conservatively (20). NAC partial or complete loss can occur but is rare. Revisions for redundant skin and dog-ears are not uncommon, ranging from $8 \%$ to $40 \%$ in the literature and are higher in the periareolar and limited scar technique $(19,20)$. Most revisions are minor and can be performed under local anesthetic.

Overall, chest masculinization has high patient reported satisfaction rates and is effective at reducing gender dysphoria and improving quality of life in female to male transgender individuals.

\section{Breast augmentation for transwomen}

Breast augmentation is desired in approximately half of transwomen (3). Guidelines for surgery are similar to chest masculinization: (I) persistent well documented gender 

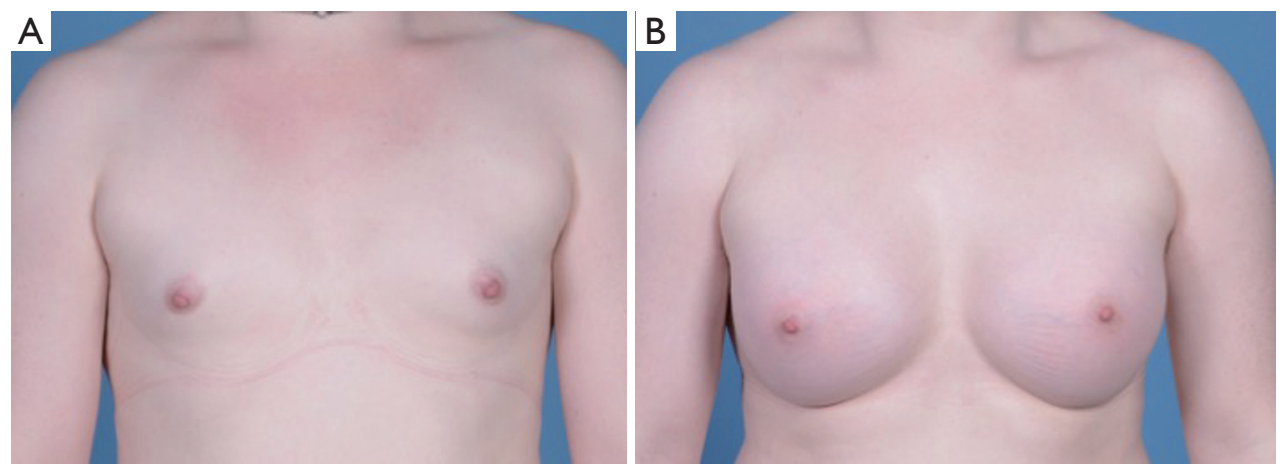

Figure 3 Chest feminization with silicone implant subglandular augmentation through inferior mammary fold incisions. (A) Before; (B) after.

dysphoria (ideally with 1 letter of support from a qualified mental health professional); (II) capacity to make a fully informed decision and to consent for treatment; (III) age of majority; and (IV) well controlled medical or mental health concerns. However it is generally recommended that patients undergo feminizing hormone therapy for 1-2 years prior to surgery to allow for maximum native breast growth (2).

Estrogen, the key hormone in the development of female secondary sex characteristics, is often administered in combination with androgen blockers such as spironolactone, which have anti-androgen, breast enhancing effects. After 1-6 months of use, fat redistributes to a more female pattern, and muscle mass diminishes. Full Tanner stage $\mathrm{V}$ development is rarely reached and many transwomen will seek breast augmentation (6).

The role of estrogen in breast cancer risk in transwomen is still not well understood (6). Current guidelines recommend annual mammography in transwomen who have been taking estrogen a minimum of 5 years. Screening is also recommended at a minimum age of 50 , but only after at least 5 years of estrogen therapy (22). For patients who are not taking estrogen, no routine screening is recommended (23). Estrogen may also contribute to increased risk of venous thromboembolism, and should be stopped two weeks prior to surgery, and resumed three weeks postoperatively, though this is controversial. Venous thromboembolism prophylaxis is mandatory (24). Smoking cessation is highly recommended, as there are known risks of wound healing complications in addition to a whole host of other health issues. All nicotine products should be stopped a minimum of 4 weeks prior to surgery, and not started until at least 4 weeks postoperatively (13).

Breast implants made of silicone or saline, are placed submuscularly, deep to pectoralis major, or in the subfascial or subcutaneous plane, overlying pectoralis major. However, in transwomen, the pectoralis muscle may increase the risk of the implants becoming superiorly and laterally displaced, so some authors advocate for subglandular placement, with careful attention to centering the implant beneath the nipples (Figure 3) (25). Breast augmentation is performed as a same day surgery, typically lasting 1 hour. Lifting and activity restrictions are imposed for a variable length of time, but at our institution, patients are typically advised to perform no heavy lifting greater than 5-10 lbs, and no high impact activities or repetitive arm motions for 4-6 weeks following surgery. The most common complications include implant malposition, capsular contracture, and asymmetry $(26,27)$. FDA recommendations emphasize that breast implants are not lifetime devices and recommend MRI screening of silicone implants for rupture three years after initial implant placement, and subsequently every two years after that (28).

Injection of silicone oil or other foreign bodies has been marketed in the non-medical community for feminization of the breasts, face, hips, buttocks or calves (6). This is not a surgically endorsed or safe form of augmentation, and has a number of complications. Alternatively, fat transfer, which consists of liposuction followed by sterile fat preparation and injection, is a surgically endorsed procedure. Fat grafting will typically result in $50-60 \%$ permanent take of the graft, and can be performed a number of times for optimal results. Common donor sites include the abdomen, flanks, and thighs.

\section{Facial feminization surgery}

Facial feminization surgery was pioneered by Dr. Douglas 
Ousterhout in the late 1980s, who initially focused on recontouring the upper facial bony skeleton (29). These techniques expanded to involve more meticulous skeletal procedures as well as alteration of key overlying soft tissue structures of the face to better align the facial aesthetic with "feminine norms." The most common of these procedures include forehead contouring, rhinoplasty, lip lift, genioplasty and chondrolaryngoplasty. Nonsurgical alternatives or adjuncts to these procedures have also been reported including fillers for lip and malar augmentation as well as neurotoxins for lateral brow elevation and treatment of rhytides (30). Facial feminization surgery is a rewarding but challenging endeavor for both the patient and surgeon (31), and requires complete investment on behalf of the surgeon in taking care of the entire patient with the help of a wellorganized multidisciplinary team.

Facial feminization requires an understanding of the anatomic differences between the male and female face that convey masculinity and femininity. While there are innumerable quantifiable variances, several critical differences are worth highlighting. Differences in the upper-third of the face are most notable with regards to forehead contour, hairline and brow position. The male forehead is flatter with prominent supraorbital bossing secondary to large frontal sinuses and greater thickness of the supraorbital ridge $(29,32)$. The male hairline tends to be more M-shaped as opposed to O-shaped in the female (33). The female eyebrow is more curved than the male, arching over instead of at the supraorbital ridge with its peak at the lateral limbus.

The female mid-face has wider zygomatic bones with more prominent, but delicate malar eminences resulting in a rounder, or more heart-shaped contour of the female face compared to the squarer male contour. This female contour can be perceived as an inverted triangle drawn by connecting a line between the two malar eminences to the chin point (34). The nose is overall smaller in females with a more concave dorsum. The glabellar angle is additionally more obtuse, as is the nasolabial angle (greater tip rotation: 100-105 degrees) with a narrower alar base and increased tip projection (35).

With regards to the lower face, overall lip height is greater in males than females (36). Females have greater upper incisor show in repose and a smaller proportion of upper lip cutaneous height to vermilion height (37). The lower face is dominated by the shape and size of the mandible. Males have a wider bigonial angle secondary to greater bony volume as well as bulk of the masseter, conveying a squarer appearance to the male face (38). The female chin is narrow, shorter, and less projected than the male chin, and can be described as a softer, rounder and less prominent feature (38). Finally, the thyroid cartilage is more prominent in males secondary to a more acute angle at the laryngeal prominence.

Preoperative considerations for facial feminization surgery are similar to other gender-affirming procedures. Guidelines according to the WPATH Standards of Care should be followed, including the documentation of gender dysphoria and the capacity to make informed decisions. Referral letters from mental health providers are not required for facial feminization procedures; however, the authors strongly believe that early involvement of mental health professionals as part of a multidisciplinary team is equally as critical in facial feminization surgery as for other gender-affirming procedures to help ensure the patient's expectations can be met. While facial feminization can be a life-saving procedure, protecting the patient from assault, bullying and alleviating gender dysphoria some insurance companies still consider it to be cosmetic and thus do not cover it. In addition to standard preoperative counseling, discussing coverage issues with patients is paramount.

Several methods of forehead recontouring have been described since the original report by Dr. Ousterhout (29). The most commonly utilized techniques involve a combination of reduction of supraorbital ridge with burring, removal and remodeling of the anterior table and creation of bony "islands" over the frontal sinus $(32,39)$. Access incisions include modified anterior hairline and bicoronal incisions that can be used for hairline advancement. Preoperative imaging is critical to evaluate the size of the frontal sinus and thickness of the frontal bone to select the most appropriate technique. Reported patient satisfaction is high $(32,39)$, though complications can be serious, and include mucocele formation, malunion of anterior table segments, and alopecia.

The goals of midface contouring include providing a rounder appearance of the facial contour while highlighting the malar prominences but minimizing the overall mass of this region of the face. Increasing the width of the zygomatic complex achieves this roundness in addition to making the orbits appear larger, which further feminizes the face. Cheek augmentation can be accomplished with alloplastic implants including both silicone and porous polyethylene implants inserted through an upper gingivobuccal sulcus incision. Fat grafting is also an important tool for malar volume augmentation and facial 
rejuvenation (40). The sandwich zygomatic osteotomy is an effective technique for increasing zygomatic width that involves a transoral osteotomy of the zygoma and lateral translation of the osteotomized segment with placement of an alloplastic or autogenous bone graft (41). Segmentalized osteotomies of the entire zygomaticomaxillary complex have also been described to increase the projection of the entire zygoma in relation to the upper third and remainder of the midface $(42,43)$.

Feminizing rhinoplasty utilizes traditional open and closed rhinoplasty techniques (44) to address the nasal dorsum, width of the bony vault, nasal length, tip projection and rotation, as well as alar width $(35,45)$. The nasal dorsum is typically addressed by performing a bony or component dorsal hump reduction, as needed, to increase the concavity of the dorsum in profile as well as create a more obtuse nasofrontal angle. Nasal bone osteotomies and infracturing can narrow a widened bony nasal vault. Tip rotation is achieved with tip rotations sutures, cephalic trim and columellar strut grafts. Further tip work can include caudal septal reduction can decrease the length of the nose and suturing of the alar domes can additionally be utilized to refine tip shape and narrow the domes. During these procedures, it is important that aesthetic assessment and operative principles (46) are still followed to appropriately individualize treatment, achieve an aesthetic as well as feminine result, and minimize the numerous complications that can lead to a poor outcome.

Lip lift procedures convey more feminine, as well as aesthetically pleasing, proportions to the upper lip (47). The goals of this operation include reducing the height of the cutaneous upper lip, increasing the height of the red vermilion, enhancing pout, achieving aesthetically pleasing dental show, and hiding the visible scar at the nasal base (48). The authors preferred technique is based on the bull's horn upper lip lift for lip rejuvenation $(49,50)$. The superior incision or final scar line is marked at the junction of the nasal base and upper lip and the planned amount of skin resection is measured with calipers at reference points on the based on the desired amount of upper lip height and incisal show (typically $5-10 \mathrm{~mm}$ simulated with a pinch technique). Meticulous atraumatic technique during excision and closure is critical to minimize aberrant scarring which is the most common complication with this procedure.

Mandibular recontouring focuses on softening the mandibular angle to decrease bigonial distance and lend a more ovoid shape to the face, as well as narrowing the width and height of the chin (51). Both genioplasty and mandibular angle reduction can be performed concomitantly through intraoral gingivobuccal and gingivolabial sulcus incisions to minimize external scars. Mandibular angle reduction can be performed using high speed burrs to reduce the prominences of the angle, body and external oblique ridge while taking care to avoid damage to the dental roots or inferior alveolar nerve (52). Osteotomies can additionally be utilized for bony reduction in patients with more prominent angles $(53,54)$, with subsequent fine contouring with burrs. The excess bulk of the masseter is a masculinizing feature which typically is reduced secondary to atrophy after stripping of the pterygomasseteric sling (34), though adjunct botulinum toxin injections can be utilized.

Feminizing genioplasty is aimed at reducing the prominence of the chin in the horizontal and vertical dimensions. While subtle changes can be made with burring or contouring, sliding genioplasty typically lends better results in our observations. A labial sulcus incision is utilized for access while leaving a cuff of mentalis for later resuspension. Osteotomies with both horizontal and a midline vertical components and removal of a predetermined segment of bone allow the surgeon to reduce the height, width and prominence of the chin (51). These segments are subsequently fixated with miniplates to each other and the native mandible, ensuring a smooth contour/ transition between the bony segments. As with traditional aesthetic genioplasty, the mental nerves must be carefully protected and inferior tooth roots avoided. Mentalis resuspension is critical as is the performance of a watertight mucosal closure to minimize the chance of salivary leak and hardware infection.

Chondrolaryngoplasty or tracheal shave reduces the masculinizing laryngeal prominence and is a powerful feminizing tool $(55,56)$. Careful burring of the laryngeal prominence of the thyroid cartilage is performed to reduce its projection and create smooth, natural contour to the neck. The authors preferred access incision is at the cervicomental junction to avoid an obvious scar in the neck. Complications include bleeding in the neck, damage to the vocal cords and destabilization of the epiglottis. Important precautions include meticulous hemostasis during the procedure and postoperative monitoring for hematoma. We additionally utilize laryngoscopy to visualize a hypodermic needle placed through the thyroid cartilage to ensure that cartilage reduction is cephalad to the level of the cords to minimize the risk of destabilization.

Facial feminization procedures are continuing to evolve 
in the landscape of technical refinements, cultural and institutional acceptance, and more critical assessment of outcomes. There is an increase in research dedicated to further improving these procedures and incorporating facial feminization into the overall care of the transgender patient. Importantly, studies have demonstrated improvements in quality of life and high patient satisfaction after facial feminization $(57,58)$.

\section{Adjunct procedures}

Liposuction and fat grafting are common cosmetic procedures that can be used to improve body contour in transmasculine, transfeminine, and non-binary individuals. Liposuction is most commonly performed in the trunk for improved contour, though it can also be performed for excess adipose tissue of the arms and legs. One of the most common risks of liposuction is contour deformity, or rippling. It is typically performed under general anesthetic, in the operating room, unless only a small area is being treated. The harvested fat, if desired, can be prepared for injection, and grafted to multiple areas ranging from the face, which is common for facial feminization, to the buttocks, which might be more desired in a transwoman. Long term survival of grafted fat ranges from $50-60 \%$, so multiple sessions can be required to achieve acceptable contour.

\section{Conclusions}

Gender affirming surgeries are critical and medically necessary elements in the treatment of gender dysphoria. The discussed treatments represent the most widely used and safest techniques, endorsed by board certified plastic surgeons. The goal for gender affirming surgeries is to improve the congruence between an individual's gender identity and their sex assigned at birth. There is a growing body of literature that demonstrates improved quality of life, reduction in the symptoms of gender dysphoria, with low rates of regret following these gender affirming surgeries. However, standardized and validated assessments of patientreported outcomes are still lacking (33), and future efforts should be aimed at better understanding long term effects on patient quality of life with validated measures.

\section{Acknowledgments}

None.

\section{Footnote}

Conflicts of interest: The authors have no conflicts of interest to declare.

Ethical Statement: The authors are accountable for all aspects of the work in ensuring that questions related to the accuracy or integrity of any part of the work are appropriately investigated and resolved.

\section{References}

1. Association AP. Diagnostic and statistical manual of mental disorders (DSM-5). Washington, D.C.: American Psychiatric Association; 2013.

2. Coleman E, Bockting W, Botzer M, et al. Standards of care for the health of transsexual, transgender, and gender-nonconforming people, version 7. Int J Transgend 2012;13:165-232.

3. The Report of The U.S. Transgender Surgey 2015, National Center for Transgender Equality. Available online: http://www.ustranssurvey.org/report. Accessed January 2019.

4. Hage JJ, Bloem JJ. Chest wall contouring for female-tomale transsexuals: Amsterdam experience. Ann Plast Surg 1995;34:59-66.

5. Wolter A, Diedrichson J, Scholz T, et al. Sexual reassignment surgery in female-to-male transsexuals: An algorithm for subcutaneous mastectomy. J Plast Reconstr Aesthet Surg 2015;68:184-91.

6. Maycock LB, Kennedy HP. Breast care in the transgender individual. J Midwifery Womens Health 2014;59:74-81.

7. Newfield E, Hart S, Dibble S, et al. Female-to-male transgender quality of life. Qual Life Res 2006;15:1447-57.

8. Agarwal CA, Scheefer MF, Wright LN, et al. Quality of life improvement after chest wall masculinization in female-to-male transgender patients: A prospective study using the BREAST-Q and Body Uneasiness Test. J Plast Reconstr Aesthet Surg 2018;71:651-7.

9. Gijs L, Brewaeys A. Surgical treatment of gender dysphoria in adults and adolescents: Recent developments, effectiveness, and challenges. Ann Rev Sex Res 2007;18:178-224.

10. van de Grift TC, Kreukels BP, Elfering L, et al. Body Image in Transmen: Multidimensional Measurement and the Effects of Mastectomy. J Sex Med 2016;13:1778-86.

11. De Cuypere G, T'Sjoen G, Beerten R, et al. Sexual and physical health after sex reassignment surgery. Arch Sex 
Behav 2005;34:679-90.

12. American Cancer Society Breast Cancer Screening Guidelines: American Cancer Society; 2018. Available online: https://www.cancer.org/latest-news/specialcoverage/american-cancer-society-breast-cancerscreening-guidelines.html

13. Krueger JK, Rohrich RJ. Clearing the smoke: the scientific rationale for tobacco abstention with plastic surgery. Plast Reconstr Surg 2001;108:1063-73; discussion 1074-7.

14. Boskey ER, Taghinia AH, Ganor O. Association of Surgical Risk With Exogenous Hormone Use in Transgender Patients: A Systematic Review. JAMA Surg 2018. [Epub ahead of print].

15. Agarwal CA, Wall VT, Mehta ST, et al. Creation of an aesthetic male nipple areolar complex in female-to-male transgender chest reconstruction. Aesthetic Plast Surg 2017;41:1305-10.

16. Cregten-Escobar P, Bouman MB, Buncamper ME, et al. Subcutaneous Mastectomy in Female-to-Male Transsexuals: A Retrospective Cohort-Analysis of 202 Patients. J Sex Med 2012;9:3148-53.

17. Berry MG, Curtis R, Davies D. Female-to-male transgender chest reconstruction: A large consecutive, single-surgeon experience. J Plast Reconstr Aesthet Surg 2012;65:711-9.

18. Monstrey S, Selvaggi G, Ceulemans P, et al. Chest-wall contouring surgery in female-to-male transsexuals: a new algorithm. Plast Reconstr Surg 2008;121:849-59.

19. Bluebond-Langner R, Berli JU, Sabino J, et al. Top Surgery in Transgender Men: How Far Can You Push the Envelope? Plast Reconstr Surg 2017;139:873e-82e.

20. Donato DP, Walzer NK, Rivera A, et al. Female-toMale Chest Reconstruction: A Review of Technique and Outcomes. Ann Plast Surg 2017;79:259-63.

21. Kääriäinen $M$, Salonen $K$, Helminen $M$, et al. Chest-wall contouring surgery in female-to-male transgender patients: A one-center retrospective analysis of applied surgical techniques and results. Scand J Surg 2017;106:74-9.

22. Deutsch M. Screening for breast cancer in transgender women. UCSF Center of Excellence for Transgender Health. 2019. Available online: http://transhealth.ucsf.edu/ trans? page=guidelines-breast-cancer-women

23. Pivo S, Montes J, Schwartz S, et al. Breast Cancer Risk Assessment and Screening in Transgender Patients. Clin Breast Cancer 2017;17:e225-7.

24. Asscheman H, T'Sjoen G, Lemaire A, et al. Venous thrombo-embolism as a complication of cross-sex hormone treatment of male-to-female transsexual subjects: a review.
Andrologia 2014;46:791-5.

25. Kanhai RC, Hage JJ, Asscheman H, et al. Augmentation mammaplasty in male-to-female transsexuals. Plast Reconstr Sur 1999;104:542-9; discussion 550-1.

26. Namnoum JD, Largent J, Kaplan HM, et al. Primary breast augmentation clinical trial outcomes stratified by surgical incision, anatomical placement and implant device type. J Plast Reconstr Aesthet Surg 2013;66:1165-72.

27. Schwartz MR. Evidence-Based Medicine: Breast Augmentation. Plast Reconstr Surg 2017;140:109e-19e.

28. U.S. Food \& Drug Administration. Type of breast implants. 2019. Available online: https://www.fda.gov/ consumers/consumer-updates/5-things-know-aboutbreast-implants

29. Ousterhout DK. Feminization of the forehead: contour changing to improve female aesthetics. Plast Reconstr Surg 1987;79:701-13.

30. Ascha M, Swanson MA, Massie JP, et al. Nonsurgical Management of Facial Masculinization and Feminization. Aesthet Surg J 2019;39:NP123-37.

31. Spiegel JH. Challenges in care of the transgender patient seeking facial feminization surgery. Facial Plast Surg Clin North Am 2008;16:233-8, viii.

32. Spiegel JH. Facial determinants of female gender and feminizing forehead cranioplasty. Laryngoscope 2011;121:250-61.

33. Morrison SD, Vyas KS, Motakef S, et al. Facial Feminization: Systematic Review of the Literature. Plast Reconstr Surg 2016;137:1759-70.

34. Altman K. Facial feminization surgery: current state of the art. Int J Oral Maxillofac Surg 2012;41:885-94.

35. Bellinga RJ, Capitan L, Simon D, et al. Technical and Clinical Considerations for Facial Feminization Surgery With Rhinoplasty and Related Procedures. JAMA Facial Plast Surg 2017;19:175-81.

36. Anic-Milosevic S, Mestrovic S, Prlic A, et al. Proportions in the upper lip-lower lip-chin area of the lower face as determined by photogrammetric method. J Craniomaxillofac Surg 2010;38:90-5.

37. Farkas LG, Katic MJ, Hreczko TA, et al. Anthropometric proportions in the upper lip-lower lip-chin area of the lower face in young white adults. Am J Orthod 1984;86:52-60.

38. Becking AG, Tuinzing DB, Hage JJ, et al. Transgender feminization of the facial skeleton. Clin Plast Surg 2007;34:557-64.

39. Capitán L, Simon D, Kaye K, et al. Facial feminization surgery: the forehead. Surgical techniques and analysis of results. Plast Reconstr Surg 2014;134:609-19. 
40. Piombino P, Marenzi G, Dell'Aversana Orabona G, et al. Autologous fat grafting in facial volumetric restoration. J Craniofac Surg 2015;26:756-9.

41. Mommaerts MY, Abeloos JV, De Clercq CA, et al. The 'sandwich' zygomatic osteotomy: technique, indications and clinical results. J Craniomaxillofac Surg 1995;23:12-9.

42. Lundgren TK, Farnebo F. Midface Osteotomies for Feminization of the Facial Skeleton. Plast Reconstr Surg Glob Open 2017;5:e1210.

43. Natghian H, Farnebo F, Lundgren KC. Management of the Midface in the Transgender Patient. J Craniofac Surg 2019. [Epub ahead of print].

44. Noureai SA, Randhawa P, Andrews PJ, et al. The role of nasal feminization rhinoplasty in male-to-female gender reassignment. Arch Facial Plast Surg 2007;9:318-20.

45. Hage JJ, Vossen M, Becking AG. Rhinoplasty as part of gender-confirming surgery in male transsexuals: basic considerations and clinical experience. Ann Plast Surg 1997;39:266-71.

46. Rohrich RJ, Ahmad J. A Practical Approach to Rhinoplasty. Plast Reconstr Surg 2016;137:725e-46e.

47. Lee DE, Hur SW, Lee JH, et al. Central Lip Lift as Aesthetic and Physiognomic Plastic Surgery: The Effect on Lower Facial Profile. Aesthet Surg J 2015;35:698-707.

48. Salibian AA, Bluebond-Langner R. Lip Lift. Facial Plast Surg Clin North Am 2019;27:261-6.

49. Cardoso AD, Sperli AE. Rhitidoplasty of the upper lip. In: Hueston JT. editor. Transactions of the fifth international congress of plastic and reconstructive surgery. Melbourne, Australia: Butterworhts, 1971:1127-9.

Cite this article as: Van Boerum MS, Salibian AA, BluebondLangner R, Agarwal C. Chest and facial surgery for the transgender patient. Transl Androl Urol 2019;8(3):219-227. doi: $10.21037 /$ tau.2019.06.18
50. Li YK, Ritz M. The modified bull's horn upper lip lift. J Plast Reconstr Aesthet Surg 2018;71:1216-30.

51. Morrison SD, Satterwhite T. Lower Jaw Recontouring in Facial Gender-Affirming Surgery. Facial Plast Surg Clin North Am 2019;27:233-42.

52. Shams MG, Motamedi MH. Case report: feminizing the male face. Eplasty 2009;9:e2.

53. Li J, Hsu Y, Khadka A, et al. Surgical designs and techniques for mandibular contouring based on categorisation of square face with low gonial angle in orientals. J Plast Reconstr Aesthet Surg 2012;65:e1-8.

54. Becking AG, Tuinzing DB, Hage JJ, et al. Facial corrections in male to female transsexuals: a preliminary report on 16 patients. J Oral Maxillofac Surg 1996;54:4138; discussion 419.

55. Wolfort FG, Dejerine ES, Ramos DJ, et al. Chondrolaryngoplasty for appearance. Plast Reconstr Surg 1990;86:464-9; discussion 470.

56. Deschamps-Braly JC, Sacher CL, Fick J, et al. First Female-to-Male Facial Confirmation Surgery with Description of a New Procedure for Masculinization of the Thyroid Cartilage (Adam's Apple). Plast Reconstr Surg 2017;139:883e-7e.

57. Ainsworth TA, Spiegel JH. Quality of life of individuals with and without facial feminization surgery or gender reassignment surgery. Qual Life Res 2010;19:1019-24.

58. Raffaini M, Magri AS, Agostini T. Full Facial Feminization Surgery: Patient Satisfaction Assessment Based on 180 Procedures Involving 33 Consecutive Patients. Plast Reconstr Surg 2016;137:438-48. 